\title{
Better to Give than to Receive: An Uncommon Commons in Synthetic Biology
}

30 Pages Posted:

\section{Andrew W. Torrance}

University of Kansas - School of Law

Date Written: 2018

\begin{abstract}
The ubiquity of the phrase "tragedy of the commons" signals its wide, and often uncritical, acceptance. Without predictable and enforceable property rights, who will maintain or improve their land? Elinor Ostrom offered an eloquent answer to this question, suggesting that governance of commons may occur on the basis of informal rules that can be effective when stakeholders believe they are fairly adaptable to changing conditions. Intellectual property has attracted a similar assumption that in the absence of exclusionary rights to prevent others from copying, making, or using inventions without permission, owners will no longer engage in innovative or creative endeavors. However, as Frischmann, Madison, and Strandburg have demonstrated, socially beneficial governance of intangible, intellectual resources too may be effective without recourse to traditional intellectual property, via norms, community standards, and democratized participation. The assumption that commons tend to descend into tragedy is difficult to test empirically, which has made it challenging to evaluate claims concerning that assumption. This chapter presents a case study that offers a rare opportunity to evaluate what can happen to rates of innovation in the absence of intellectual property protection.
\end{abstract}

Keywords: invention, innovation, technology, technological innovation, user innovation, free innovation, collaborative innovation, open innovation, household innovation, intellectual property, patent

JEL Classification: D13, K2, K23, O1, O14, O17, O25, O3, O30, O31, O32, O33, O34, O35, O38, O39

\section{Suggested Citation:}

Torrance, Andrew W., Better to Give than to Receive: An Uncommon Commons in Synthetic Biology (2018). Available at SSRN: https://ssrn.com/abstract=3135317 